\title{
Climatological Beam Propagation Conditions for China's Weather Radar Network
}

\author{
HONGYAN WANG, GAILI WANG, AND LIPING LIU \\ State Key Laboratory of Severe Weather, Chinese Academy of Meteorological Sciences, Beijing, China
}

(Manuscript received 13 April 2017, in final form 30 September 2017)

\begin{abstract}
The vertical refractivity gradient (VRG) is critical to weather radar beam propagation. The most common method of calculating beam paths uses the 4/3 Earth radius model, which corresponds to standard refraction conditions. In the present work, to better document propagation conditions for radar electromagnetic waves, which is essential for hydrology and numerical weather forecast models to more fully benefit from observations taken from the new-generation weather radar network in China, VRG spatial and temporal variations in the first kilometers above the surface are explored using 6-yr sounding observations. Under the effects of both regional climatic and topographic conditions, VRG values for most of the radars are generally smaller than those of the standard conditions for much of the year. There are similar or slightly larger values at only a few radar sites. Smaller VRG values are more frequent and widespread, especially during rainy seasons when weather radar observations are important. In such conditions, beam heights estimated using standard atmospheric refraction are overestimated relative to actual heights for most of the radars. Underestimates are much less common and of much shorter duration. However, height deviations are acceptable for being well within the uncertainty of radar echo height owing to the $\sim 1^{\circ}$ beamwidth. In coastal areas and the middle and lower reaches of the Yangtze River, radar observations should be applied with much more caution because of the greater risk of beam blockage and clutter contamination.
\end{abstract}

\section{Introduction}

Weather radars are important measurement instruments widely used in modern meteorological services. Radar observations are not just applied directly for monitoring and early warning of disastrous weather events such as severe convection, typhoons, and rainstorms, but are also used as input to data assimilation systems to improve initial conditions for numerical forecast models. The effect of electromagnetic wave propagation on radar observations is an essential issue for radar users and researchers. Radar beam propagation mainly depends on the vertical refractivity gradient (VRG), so the radar beam height can be calculated using the VRG. The VRG is a direct result of local thermodynamic conditions, which vary substantially in space and time. Sometimes, vertical refractivity gradients are quite sharp. Examples are nighttime clear skies resulting in a temperature inversion and rapid decrease of humidity with altitude, warm and dry airflow over cooler water that is cooled and moistened in its lower

Corresponding author: Hongyan Wang, whyan@camscma.cn layers, and storm outflows (Caumont et al. 2006). Sharp vertical refractivity gradients introduce problems, that is, there may be large errors in the calculated radar beam height (Sweezy and Bean 1963), which are detrimental to the application of radar data to precipitation assessment and forecasting (Bellon et al. 2007; Wang et al. 2013), three-dimensional radar mosaics (Zhang et al. 2005; Xiao et al. 2008), and numerical data assimilation (Gao et al. 2006). Such gradients cause abnormal refraction and, as a result, radar beams bend to the ground. The result is that radar echoes contain substantial ground clutter and low-quality observations, introducing errors into radar-based quantitative precipitation products (Moszkowicz et al. 1994; Sharif et al. 2004; Fornasiero et al. 2005) or numerical models (Zeng et al. 2014). As a case in point, the distribution of ground echoes in the Bordeaux region due to anomalous propagation was derived by applying terrain data (Mesnard and Sauvageot 2010). Additionally, strong beam blockage and additional errors in reflectivity estimation are generated when radar beams bend abnormally to the ground, causing difficulties in precipitation estimation (Bech et al. 2003, 2007b; Fornasiero et al. 2006). 
Physical processes in the troposphere are too complex to be limited to only statistical descriptions of spatial and temporal characteristics of atmospheric refractivity. Nevertheless, statistics of major refractivity parameters such as the average vertical gradient are extremely useful in the practical design of terrestrial radio paths when long-term statistics of the received signal must be estimated (Grabner and Kvicera 2011). As early as the 1950s, Bean and Dutton (1966) had systematically studied atmospheric refractivity, presented its global distribution, and constructed a simple model of its vertical distribution (Bean and Horn 1959; Bean and Dutton 1966). The International Telecommunication Union (ITU) regularly issues guidance products for global distribution regarding refractivity and VRG within $1 \mathrm{~km}$ of the surface, based on 5-yr observations (1955-59) at 99 sounding stations around the globe (ITU 2012). However, these products with large scale but poor spatial resolution may be inadequate for local use. Further study by Grabner and Kvicera (2011) showed that the atmospheric refractivity gradient in the lower troposphere (within $120 \mathrm{~m}$ of the surface) can vary from -500 to $50 \mathrm{~N}$ units $\mathrm{km}^{-1}$. After analyzing the variation of radio refractivity in Lithuania within $1.2 \mathrm{~km}$ of the surface on 4 and 28 November 2010 , Valma et al. (2010) revealed a regional vertical gradient of radio refractivity smaller than the value recommended by the ITU. In the 1990s, to increase the accuracy of weather radar observations, characteristics and temporal variations of atmospheric refraction in certain Chinese regions were investigated using sounding data (Zhang et al. 1991; Dai et al. 1993, 1996). In those studies, large seasonal variations in the vertical distribution of atmospheric refraction were found. The error was largest when the 4/3 Earth radius model is used. So an improved statistical model was advanced to reveal local vertical distributions of refraction at various regions and sites. In Barcelona, Bech et al. (2002) studied seasonal variations of propagation conditions in the first kilometer above the surface using radiosonde data. Chang and Zhang (2004) discussed and developed a theoretical model to simulate VRG distributions near the surface. Ali et al. (2012) evaluated the sensitivity of radio refractivity to temperature, pressure, and humidity over a period of 10 years, observing that radio refractivity reaches maximum values during the hot and humid months of July and August. In recent years, studies were conducted to obtain detailed refractivity information in West Africa (Falodun and Ajewole 2006; Adediji et al. 2011; Ayantunji et al. 2011). Saleem (2016) used satellite remote sensing data to investigate the spatiotemporal variability of a modified refractivity gradient at the $700-\mathrm{hPa}$ pressure level over regions of the Middle East. A numerical weather prediction (NWP) model was used to evaluate atmospheric structure at high resolution (Atkinson and Zhu 2006; von Engeln and Teixeira 2004; Bech et al. 2007a,b; Lopez 2009; Magaldi et al. 2016) to describe or forecast microwave propagation conditions. The principal focus was on superrefraction, which involves problems that have received greater attention by researchers (Brooks et al. 1999; Atkinson and Zhu 2006; Chang and Lin 2011).

Radio propagation conditions cause the radar beam to have different paths, either higher or lower than normal (Bech et al. 2003). Fornasiero et al. (2005) computed radar beam paths based on sounding data and derived atmospheric refractivity for radar beam propagation using dynamic ground clutter maps and beam blockage diagrams. Using local model outputs and different sounding datasets, conditions for radar beam propagation in the Po Valley of Italy have been investigated (Fornasiero et al. 2006). As a quality control of the radar quantitative precipitation estimation, Bech et al. (2003) evaluated the variability of radio propagation conditions and modeled beam propagation using the VRG from three-dimensional NWP fields to correct beam blockages for quantitative precipitation estimation, indicating that although beam blockage correction is generally robust, with 1-dB departures from standard propagation conditions less than $10 \%$ of the time, extreme anomalous propagation cases would produce greater differences. To optimize the results of radar data assimilation, Gao et al. $(2006,2008)$ investigated methods of tracing beam paths and examined the sensitivity of radar electromagnetic wave paths to vertical changes in atmospheric temperature and humidity. They showed that a strong increase in the magnitude of VRG leading to radar beam path deviation is often attributable to dramatic humidity changes accompanied by severe weather events. Bodine et al. (2011) also found that refractivity is most sensitive to moisture, leading to considerable diurnal differences. Works to extract near-surface atmospheric refraction information by ground clutter echoes were done by Fabry et al. (1997) and Park and Fabry (2011). Fabry et al. (1997) obtained the refractive index using radar phase measurements from ground targets. Park and Fabry (2011) estimated instantaneous VRGs from the ground clutter distribution, assuming that ground echo coverage varies with the VRG. Zeng et al. (2014) compared three beam tracing methods to ascertain their reliability and accuracy.

The most common and simple method of calculating radar beam height uses the 4/3 Earth radius model, which is based on climatological conditions at the midlatitudes 

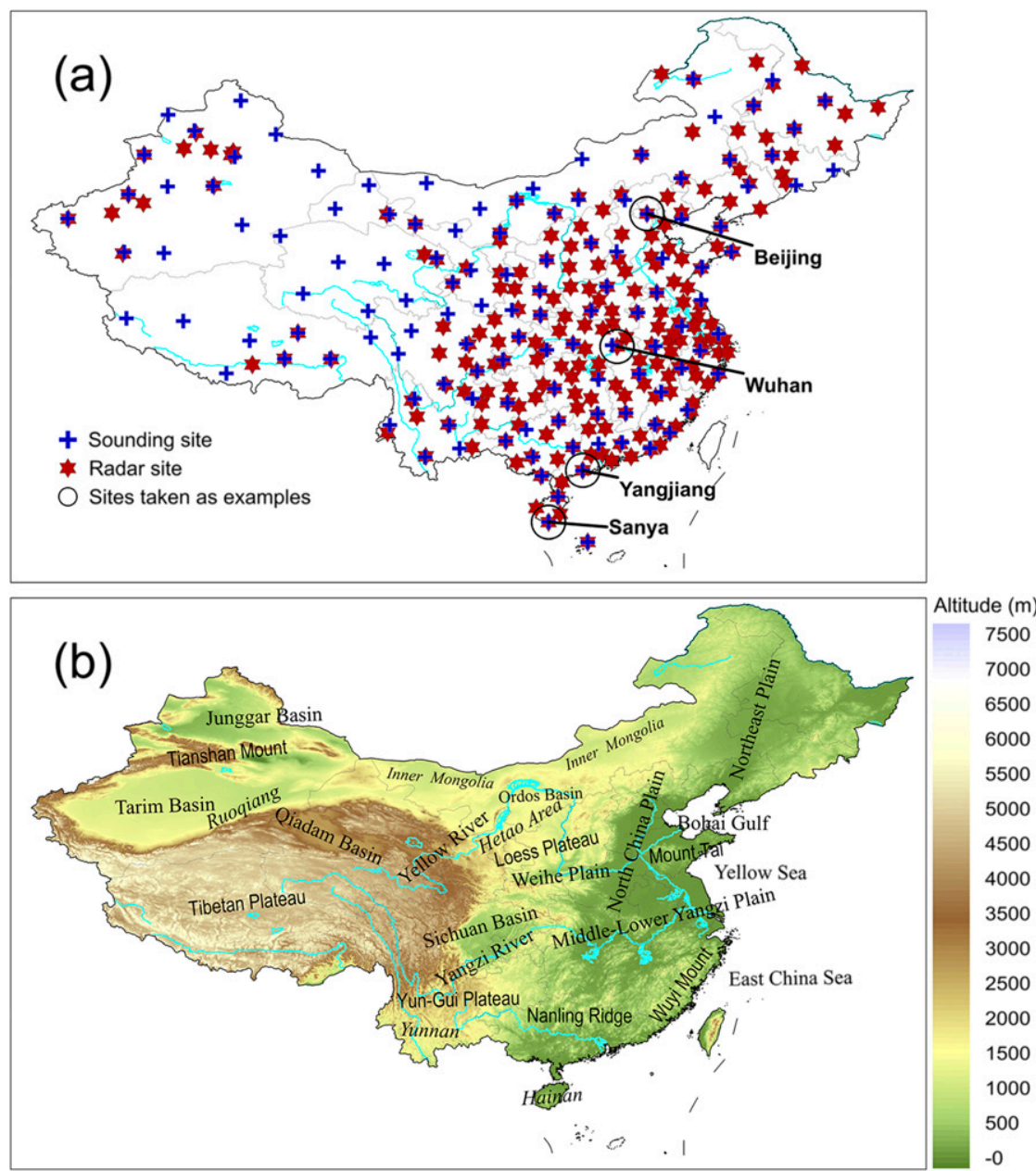

FIG. 1. (a) Weather radars put into operation by the end of 2015 and sounding stations in China. (b) Terrain of mainland China, with locations of interest marked by text.

of the Northern Hemisphere, and so does China's newgeneration radar network. However, that network contains more than 200 radars and mainly covers midto low-latitude regions. Thus, atmospheric temperature, pressure, and humidity vary widely with area and elevation, causing changes in VRG that differ substantially from standard refraction conditions. Seasonal variation of the refractivity gradient can cause microwave system unavailability under some certain abnormal conditions (Serdega and Ivanovs 2007). Therefore, the present study is intended to better document the refraction conditions and their effects from the viewpoint of China's operational weather radars. In the study, VRG spatiotemporal variations in the first kilometer were disclosed using 6-yr observational data from sounding stations in China (Fig. 1a). Refractivity conditions and their impacts on radar beam propagation are also addressed with consideration of the radar network distribution.
This paper is organized as follows: Section 2 briefly introduces the theoretical basis and method for the computation of atmospheric refraction and its vertical gradient. Section 3 analyzes statistical results of the VRG near the surface in China. Section 4 addresses the VRG influence on beam paths of operational weather radars. Then, a summary is presented in section 5 .

\section{Methodology \\ a. Refractive index}

The refractive index and its vertical distribution are dependent on actual atmospheric conditions (Smith and Weintraub 1953; Fabry et al. 1997; Steiner and Smith 2002). For microwave band electromagnetic wave propagation in the atmosphere, atmospheric refraction is a function of temperature, humidity, and pressure and can be expressed as follows: 


$$
N=(n-1) \times 10^{6}=77.6 \frac{P}{T}+3.73 \times 10^{5} \frac{e}{T^{2}},
$$

where $P, T$, and $e$ are pressure $(\mathrm{hPa})$, temperature $(\mathrm{K})$, and water vapor pressure, respectively; $n$ is the atmospheric refractive index, usually expressed in terms of refractivity $N$. Using sounding data and Eq. (1), $N$ at different levels and its vertical gradient can be determined.

\section{b. VRG model}

Based on the layers model (Zhang et al. 1991; Dai et al. 1996), the refractive index changes linearly with height in the 1-km layer above the surface [Eq. (2)], but changes exponentially with height above that level (equation not shown):

$$
N(h)=N_{s}+\left(h-h_{s}\right) \times G \quad h_{s} \leq h \leq h_{s+1},
$$

where $h_{s}$ and $h_{s+1}$ are the surface elevation and 1-km height above the surface, respectively; $N_{s}$ and $N(h)$ are the refractivities at the surface and at $h$, respectively; $G$ is the vertical gradient of the refractive index. At a single time, $N\left(h_{s+1}\right)$ is obtained by linear interpolation unless it can be obtained directly at $1-\mathrm{km}$ height, and $G$ is its difference with $N_{s}$ (ITU 2012). The statistical $G$ is determined by the method used by Zhang et al. (1991) and Dai et al. (1996). That is, there is a strong statistical correlation between $G$ and $N_{s}$ as follows:

$$
G=-A \times \exp \left(B N_{s}\right) .
$$

Here, $A$ and $B$ are determined by regression. Then, given the monthly average $N_{s}$, the monthly $G$ is obtained.

\section{c. Radar beam propagation}

The beam transmitted by a weather radar is assumed to be a single electromagnetic radiation ray. The initial elevation angle of this ray is that of the radar beam center. The atmosphere is divided into thin layers in the vertical. When the ray passes from a layer to the one above, it follows Snell's law, that is, the change of ray elevation is related to the vertical gradients of the refractive index between the two layers.

\section{1) Equivalent EARTH RAdiUS METHOD}

The equivalent Earth radius method is the most common. The refractive index varies linearly with height at all levels, but the curvature of a radar ray relative to Earth's surface does not vary with height. Thus, the ray can be treated as a straight line, and the equivalent Earth radius $R^{\prime}$ is computed by Doviak and Zrnić (1993):

$$
R^{\prime}=\frac{1}{1+R_{e} \frac{d n}{d h}} R_{e},
$$

where $R_{e}$ is Earth's radius and $d n / d h$ is the vertical gradient of the refractive index. The common approximation is $R^{\prime}=(4 / 3) R_{e}$, representing the climate mean state in the atmospheric boundary layer at the midlatitudes of the Northern Hemisphere. Using the equivalent Earth radius, beam height $h$ can be calculated from the trigonometric function relationship:

$$
h=\sqrt{r^{2}+R^{\prime 2}+2 r R^{\prime} \sin (e)}-R^{\prime},
$$

where $r$ is slant range from the radar, and $e$ is the elevation angle.

\section{2) Multilayer tracing Method}

When $d n / d h$ varies with height, the method of equivalent Earth radius cannot accurately describe the propagation of the radar ray as mentioned earlier, and actual vertical variations of the refractive index must be considered. In such a situation, the multilayer tracing method based on sounding observations can give more realistic propagation paths (Caumont et al. 2006; Gao et al. 2006; Zeng et al. 2014).

Starting from the radar antenna, the beam ray is divided into segments with small intervals, each segment corresponding to a thin horizontal layer relative to the surface (here, $25 \mathrm{~m}$ per layer). The bottom of the first layer is located at the radar antenna, followed by the second and subsequent layers in sequence. For any layer, its bottom and top are at heights $h_{b}$ and $h_{t}$, respectively, and its elevation angle is $e_{b}$. The travel distance of the beam is $\Delta r$, and the top of the layer is the bottom of the one above. Using a trigonometric function relationship, we have

$$
h_{t}=\sqrt{\Delta r^{2}+\left(R_{e}+h_{b}\right)^{2}+2 \Delta r\left(R_{e}+h_{b}\right) \sin \left(e_{b}\right)}-R_{e} .
$$

The elevation angle at the next layer is given by Fornasiero et al. (2006):

$$
e_{t} \cong \tan ^{-1}\left( \pm \frac{\left\{\left(R_{e}+h_{b}\right)^{2} \sin ^{2}\left(e_{b}\right)+2\left(R_{e}+h_{b}\right)\left(h_{t}-h_{b}\right)\left[1+\left(R_{e}+h_{b}\right) \frac{d n}{d h}\right]\right\}^{1 / 2}}{\left(R_{e}+h_{b}\right) \cos \left(e_{b}\right)}\right)
$$


The value of $d n / d h$ is calculated by

$$
d n / d h=\frac{N_{t}-N_{b}}{h_{t}-h_{b}} \times 10^{-6},
$$

where $N_{t}$ and $N_{b}$ are the refractivities of the current layer and the one above.

\section{d. Data and statistical calculations}

Observational data from sounding stations during 2010-15 were used for the refractivity calculation and statistics. Figure 1a shows the sounding stations used and operational weather radars at the end of 2015 . Owing to topography (Fig. 1b) and population density, most radar sites are east of the Tibetan Plateau, whereas only a few are deployed in the vast region of western and northern China. Sounding stations are not as dense as radar sites, but fortunately those stations are usually near radar sites. Therefore, data from these stations can represent conditions for radar beam propagation.

Variations of refractivity in the first kilometer of altitude are considered important and have been extensively discussed (Bech et al. 2002; Abu-Almal and Kifah 2010; Park and Fabry 2011; ITU 2012). The findings of these studies support the use of the linear-variation layer used in the present study [Eq. (2)]. The VRG under standard refraction is also assumed in the first kilometer of the atmosphere (Serdega and Ivanovs 2007). We also focused on the atmospheric layer below $1 \mathrm{~km}$. Equation (1) was used to compute the vertical profile of atmospheric refractivity. Then, a statistical value of $G$ was retrieved using Eq. (3). Further, the humidity component is corrected (Cheng and Zhang 2014; Hao et al. 2015) before use in Eq. (1).

The lowest $0.5^{\circ}$ elevation angle of the operational weather radars was used to analyze the characteristics of radar beam path that are most affected by refractive conditions (Park and Fabry 2011). The antenna beamwidth is $\sim 1^{\circ}\left(0.95^{\circ}\right.$ for most of the radars $)$. The beam path under the standard refraction condition was computed by Eq. (5). Using actual observation data, all beam paths calculated by Eqs. (6) and (7) were assumed correct. Considering that the path of the principal lobe is split into small rays (Fornasiero et al. 2005; Wang et al. 2014), the radar beam center, top, and bottom can be calculated separately.

\section{Climatological features of VRG}

Figure 2 presents monthly values of VRG statistics in the first kilometer. Figures $2 \mathrm{a}$ and $2 \mathrm{~b}$ are for 0000 and 1200 UTC, respectively. References to topography and locations in this section are labeled in Fig. 1b.

\section{a. Spatial variations}

The values of $G$ over the Tibetan Plateau are the largest, between -35 and $-15 \mathrm{~km}^{-1}$ throughout the year. This is because water vapor content there is always very low and has a small seasonal change. In Inner Mongolia, most values are close to $-35 \mathrm{~km}^{-1}$ in winter and $-45 \mathrm{~km}^{-1}$ in summer, similar to those over the Loess Plateau in winter. However, negative values of $G$ can reach $-55 \mathrm{~km}^{-1}$ in the Great Bend of the Yellow River, and $-60 \mathrm{~km}^{-1}$ over the Weihe Plain in summer, when warm, moist air from the east crosses that plain and the Loess Plateau to amass over the Ordos basin. In the middle and lower reaches of the Yangtze River valley and Sichuan basin, values are between -70 and $-40 \mathrm{~km}^{-1}$, and remain smaller than $-55 \mathrm{~km}^{-1}$ during May-October, when northerly and southerly winds meet to produce warm, moist air. Cold air can readily accumulate at low levels because of local mountain-valley circulations, producing inversions or small lapse rates favorable to increasing $|G|$ in basins. In general, there is a small-value center around the middle and lower reaches of the Yangtze River and a weaker center in the Sichuan basin year-round. Under the influence of moist airflow from the ocean, there are also small values in the coastal area along the Yellow Sea and southern Bohai Sea, between -70 and $-40 \mathrm{~km}^{-1}$; the smallest values are around Hainan Island, between -90 and $-50 \mathrm{~km}^{-1}$. Accordingly, superrefraction is frequently observed near coastal radars (Bech et al. 2003; Atkinson and Zhu 2006; Chang and Lin 2011). There are centers of small values in basins on both sides of the Mount Tai most of the time, because of persistent temperature inversions. Indeed, the smallest value of $-80 \mathrm{~km}^{-1}$ is in Ruoqiang, accompanied by a strong nighttime inversion. Because of warm, moist air transport through the Qaidam basin in summer (Lin and Zheng 1992), strong differences in water vapor content between summer and winter cause large changes of $G$ at the edge of the Tarim basin (Yang et al. 2010); values are less than $-50 \mathrm{~km}^{-1}$ in summer and larger than $-30 \mathrm{~km}^{-1}$ in winter, which are unique in northwest China.

\section{b. Temporal variations}

Generally, the smallest value of $G$ is during MayOctober, and the largest value is during December-April, although the exact time varies by region. The largest and smallest values are found during the following months, respectively: January-March and July-August over the Tibetan Plateau; April and July-August over Inner Mongolia and the Loess Plateau; February and MayOctober in the middle and lower reaches of the Yangtze River; January-February and May-August south of the 

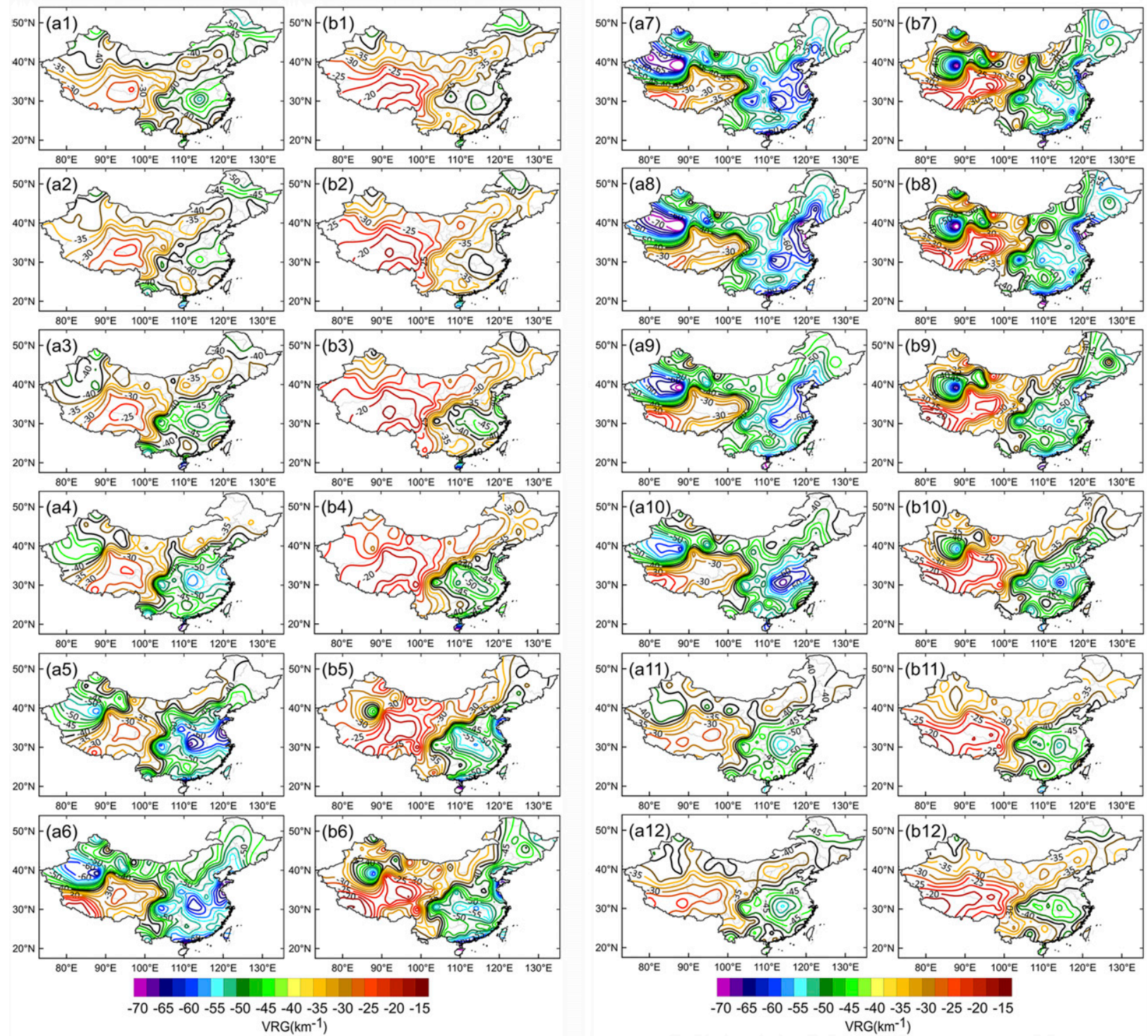

FIG. 2. Spatial distribution of VRG near the surface at (a1)-(a12) 0000 and (b1)-(b12) 1200 UTC for each month. Labels 1-12 stand for January-December. VRG is shown by colored contours with labels.

Yangtze and in south China; December-January and July-August along the Bohai Gulf; February and MayAugust in the Sichuan basin; December-January and May near Hainan Island. As a result, contour lines gradually move southeast during August-February and retreat northwest during February-July. In July and August, $G$ is no larger than the standard value $\left(-40 \mathrm{~km}^{-1}\right)$ everywhere except over the Tibetan Plateau in the morning and is smaller throughout China's central, eastern, and southern sections in the evening. In February, the values are no smaller than the standard except over the Hainan Islands, southern Yunnan, and the plain regions in the morning and over the middle and lower reaches of the Yangtze
River and Sichuan basin in the evening. The above findings indicate that temporal variations of the VRG spatial distribution near the surface in China are synchronized with that of the rainy season. Large vertical changes of moisture are frequent in environments with abundant water vapor content, which are likely to cause strong vertical refractivity gradients. This is supported by Gao et al. (2008) and Ali et al. (2012).

Most values of $G$ over mainland regions in the morning (Fig. 2a) are generally smaller by $5-10 \mathrm{~km}^{-1}$ than in the evening (Fig. 2b). From Fig. 2, there are large differences along the northern margin of Tarim basin (about $10-25 \mathrm{~km}^{-1}$ ) where the air is dry with small water 
vapor content, and strong nighttime inversions have powerful impacts. In coastal regions, where water vapor contents are large and diurnal temperature variations are slight, there are few differences between morning and evening values. Actually, the diurnal variation of temperature plays the major role in the $G$ difference between morning and evening.

Our findings generally agree with monthly VRG values in the first kilometer for February, May, August, and November suggested by the ITU (2012). The present work provides topography-dependent changes of VRG with much finer spatial distribution to meet the needs of the weather radar network.

\section{c. Changes of VRG with elevation}

Spatial distributions of $G$ shown in Fig. 2 also indicate that the VRG near the surface is closely correlated with topography. In China's interior, elevations of the Tibetan Plateau are the highest, and $G$ is the largest. Along transitional zones in rugged areas, such as the Tibetan Plateau periphery, southeast rim of the Inner Mongolia Plateau, and eastern and southern edges of both the Loess and Yun-Gui Plateaus, the topography changes sharply, as do VRG spatial variations. In hilly areas of southeast China, values are slightly larger than in surrounding areas at lower altitudes, generally with differences around $5 \mathrm{~km}^{-1}$. Such examples are shown at the edges of Mount Wuyi and the Nanling region.

The scatter graph in Fig. 3 shows VRG change with surface elevation (MSL). Here, values of $G$ were calculated based on all the data from 2010 to 2015, not for each month. Values of stations at similar elevations scatter in a certain range because of varying local atmospheric conditions, and the values generally increase with station elevation, increasing by $\sim 6 \mathrm{~km}^{-1}$ per kilometer on average. Values within $\sim 1400 \mathrm{~m}$ in the morning and $\sim 300 \mathrm{~m}$ in the evening are not larger than those under standard conditions at the majority of locations. The opposite holds at higher elevations.

\section{Influence on operational weather radar}

\section{a. Propagation conditions}

\section{1) Role OF RADAR SPATIAL LOCATION}

Given the uneven distribution of operational weather radars in China, the percentages of radars corresponding to various $G$ values from the nearest sounding station are given in Fig. 4. Here, the value at the nearest sounding station is used to represent the environmental refraction of the radar. In both Figs. $4 \mathrm{a}$ and $4 \mathrm{~b}$, except for the period of January-March during the evening,

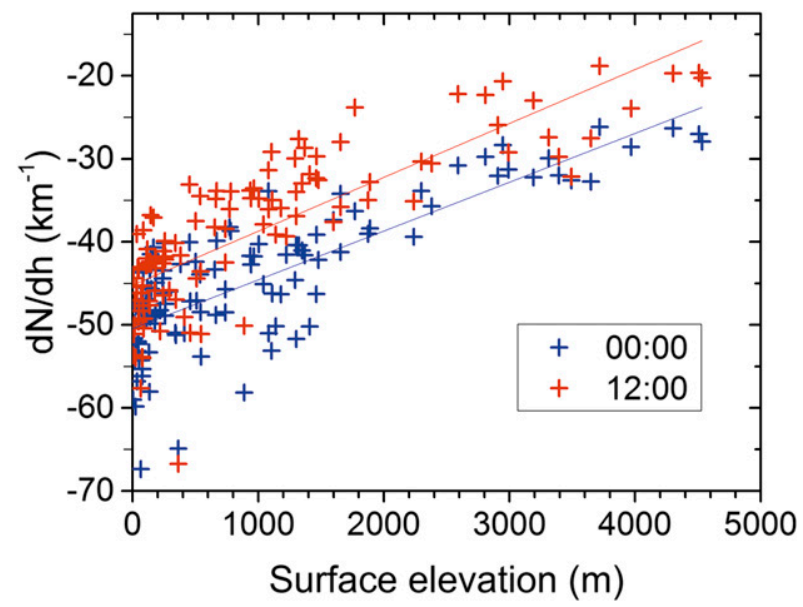

FIG. 3. Scatterplot of multiyear statistical VRG with surface elevations. Blue plus signs represent VRG points for $0000 \mathrm{UTC}$, and red plus signs represent points for 1200 UTC.

values corresponding to the largest percentages are smaller than under standard conditions. The $G$ corresponding to the largest percentage of radars is smallest in July and August, and largest in January-March. In the morning, the minimum and maximum values are from -60 to $-55 \mathrm{~km}^{-1}$ and from -45 to $-40 \mathrm{~km}^{-1}$, respectively. For the maximum percentages, $G$ values for all radars are mainly from -60 to $-20 \mathrm{~km}^{-1}$. For minimum percentages, those values are mainly from -80 to $-35 \mathrm{~km}^{-1}$. The number of radars varies uniformly for some $G$ ranges over a long period between April and November. There is a similar feature in the evening, but $G$ values corresponding to the largest percentages are larger than in the morning, by $5-10 \mathrm{~km}^{-1}$. From April through October, the warm and rainy season, which is a critical period for weather radar observations, $70 \%-80 \%$ of the radars have $G$ values smaller than the standard refraction gradient by $5-40 \mathrm{~km}^{-1}$. Only a few radars have values $\geq-20 \mathrm{~km}^{-1}$.

\section{2) ROLE OF RADAR HEIGHT}

Radar elevation also determines its refractive conditions, basically in the way described in section 3 (Fig. 3). The elevation of a ground-based radar is determined by the elevation of the ground and the tower height. For China's operational weather radars, tower heights vary greatly. For simplicity, radar elevation was taken as the site elevation. In Fig. 5, between 100- and 200-m elevations, the number of radars is the largest $(\sim 19 \%)$, followed by those between 0 and $100 \mathrm{~m}(15 \%)$. In the morning, annual statistical values of VRG are from -60 to $-45 \mathrm{~km}^{-1}$ below $100 \mathrm{~m}$, and from -55 to $-40 \mathrm{~km}^{-1}$ between 100 and $200 \mathrm{~m}$ (Fig. 3). In the evening, values are larger by $\sim 5 \mathrm{~km}^{-1}$. Radars below $\sim 1400 \mathrm{~m}$ and 

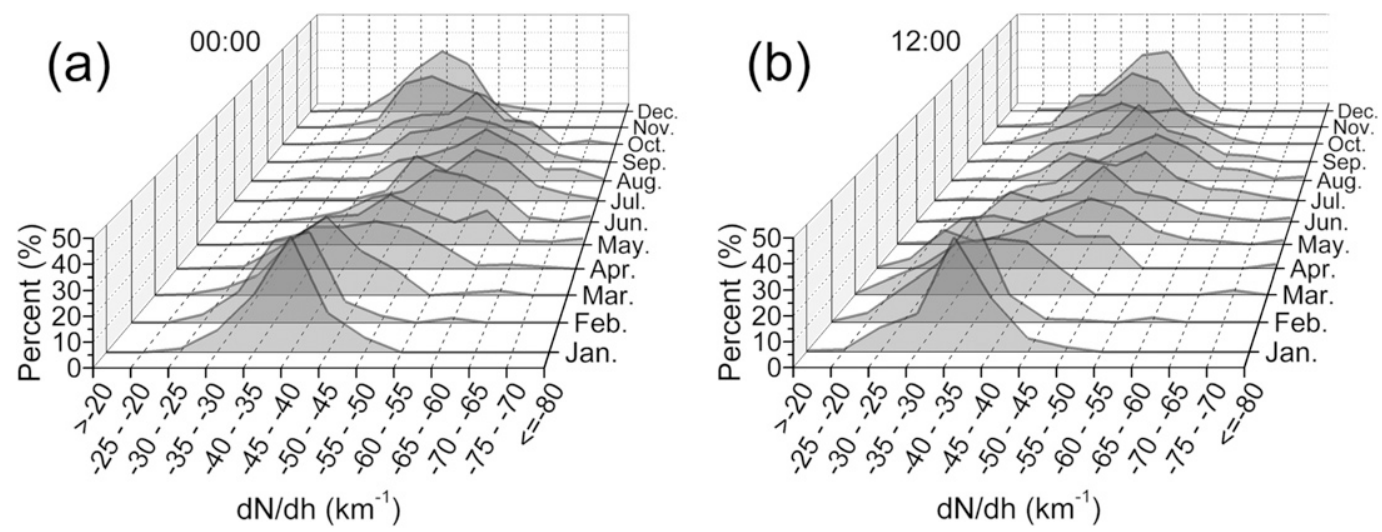

FIG. 4. Percentages of weather radars with VRG values at (a) 0000 and (b) 1200 UTC for each month.

$300 \mathrm{~m}$ constitute $\sim 83 \%$ and $43 \%$, respectively. VRG values are not larger than the standard value below $1400 \mathrm{~m}$ in the morning and below $300 \mathrm{~m}$ in the evening. For radars above $2000 \mathrm{~m}(<10 \%$; Fig. 5), VRG values are larger than the standard value in both the morning and the evening, about -30 and $-25 \mathrm{~km}^{-1}$, respectively. Values are smaller in the warm, moist season.

\section{b. Deviation of radar beam height}

\section{1) Height determination}

Radar beam heights of different VRGs can be computed by Eq. (6). The so-called relative deviations, which are the difference divided by the beamwidth under standard conditions (Gao et al. 2008), are presented as a reference for measuring the errors considering the sampling scales of Chinese radars. If the value of $G$ is larger than the standard value of $-40 \mathrm{~km}^{-1}$, the actual elevation is higher than the one estimated using the standard VRG; otherwise the opposite is the case. A greater departure of $G$ from the standard value makes for a larger error. Starting from the standard VRG, absolute deviations at a distance of $70 \mathrm{~km}$ from the radar change by $\sim 25 \mathrm{~m}$ for a $10 \mathrm{~km}^{-1}$ increase (or decrease) of $G$. The statistical boundary values of $G,-20$ and $-80 \mathrm{~km}^{-1}$, cause deviations of approximately -50 and $100 \mathrm{~m}$ at a range of $70 \mathrm{~km}$, corresponding to relative deviations around $-4 \%$ and $8 \%$, respectively. For a certain value of $G$ not equal to $-40 \mathrm{~km}^{-1}$, the absolute deviations are smaller at closer ranges and greater at further ranges; deviations are from -25 to $50 \mathrm{~m}$ at a $50-\mathrm{km}$ distance for $G$ between -20 and $-80 \mathrm{~km}^{-1}$, corresponding to relative deviations from about $-3 \%$ to $6 \%$. If the statistical $G$ is used at farther ranges (i.e., levels above $1 \mathrm{~km}$ ), (relative) deviations are from about -100 to $400 \mathrm{~m}$ (from $-6 \%$ to $24 \%$ ) at a $200-\mathrm{km}$ distance.
Four sites within key regions of the weather network, Beijing, Wuhan, Yangjiang, and Sanya, were taken as examples to illustrate actual beam-height deviations. Each radar is near a sounding station (marked by thick circles in Fig. 1a). Monthly average beam heights for the $0.5^{\circ}$ elevation angle were calculated based on sounding data, using a multilayer tracing method. Differences between average heights and heights under standard conditions of the beam center and bottom are depicted in Fig. 6.

Variations of deviations with time are consistent with statistical VRG. The lowest actual beams are between May and October, and the highest beams are in January or February. There are slight underestimates at Beijing in winter, but overestimates every month at Wuhan and Sanya, in both the morning and evening. There are overestimates at all sites in summer. Deviations for Beijing are slightly larger than at other sites in winter, and deviations at Sanya are largest in summer. For

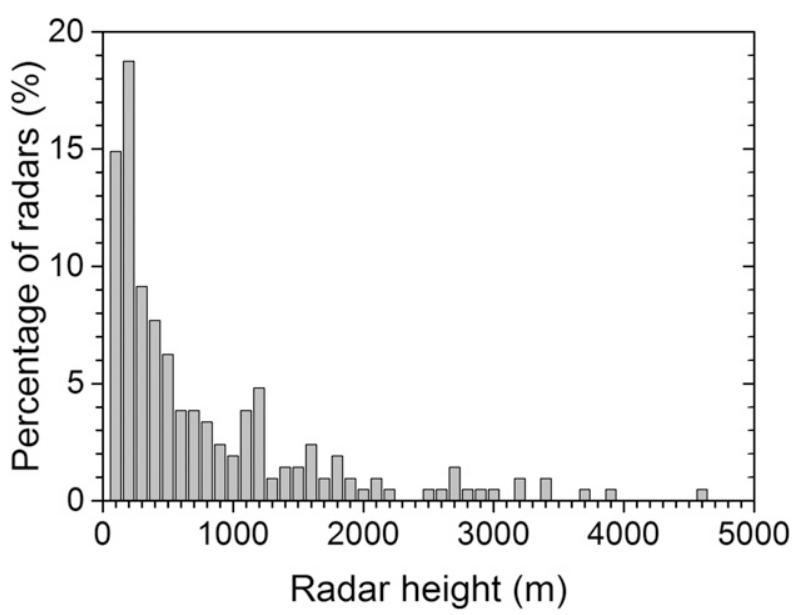

FIG. 5. Percentages of weather radars at various elevations. 

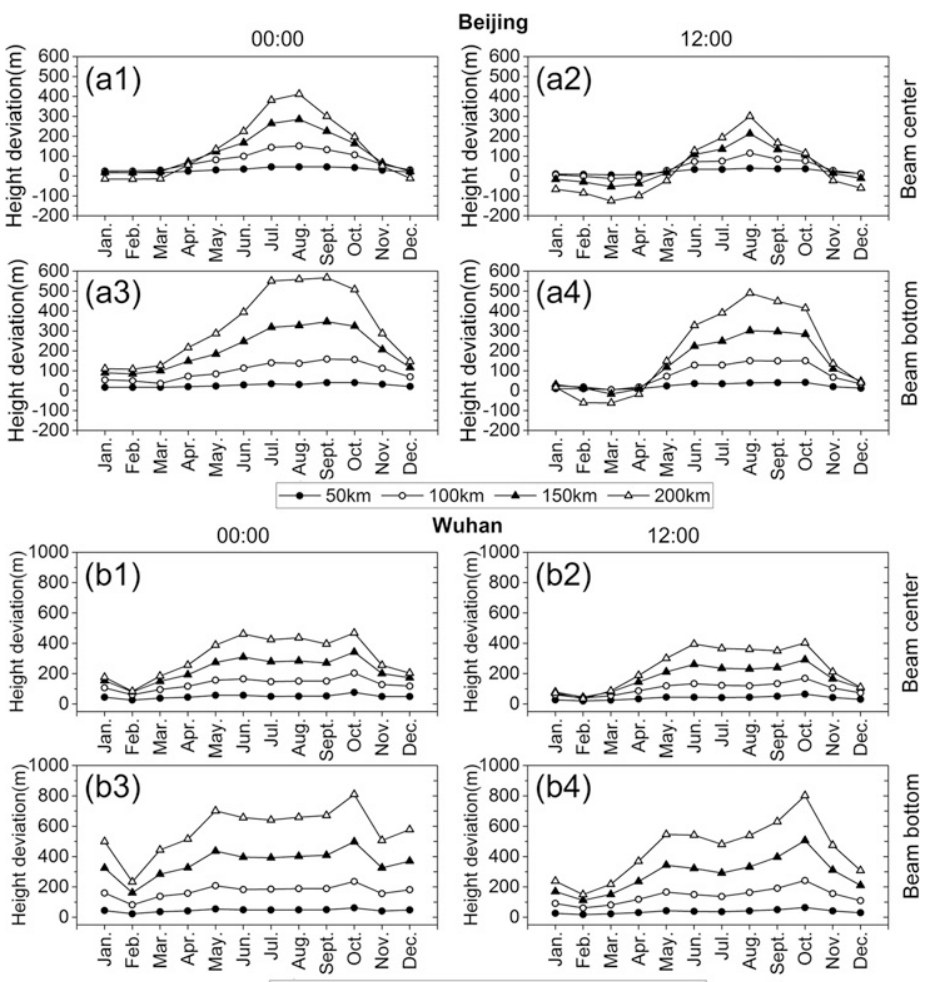

Wuhan $12: 00$

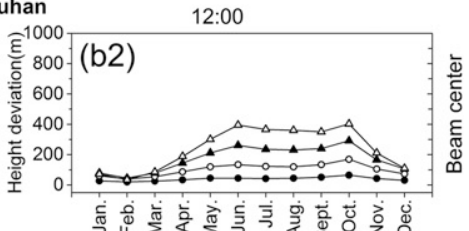

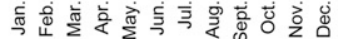

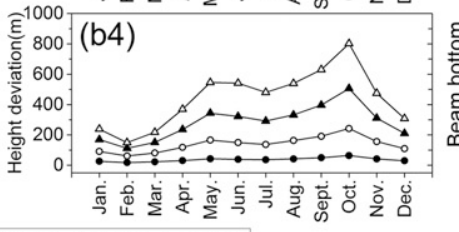

$\rightarrow 50 \mathrm{~km} \multimap 100 \mathrm{~km} \leadsto 150 \mathrm{~km} \rightarrow-200 \mathrm{~km}$
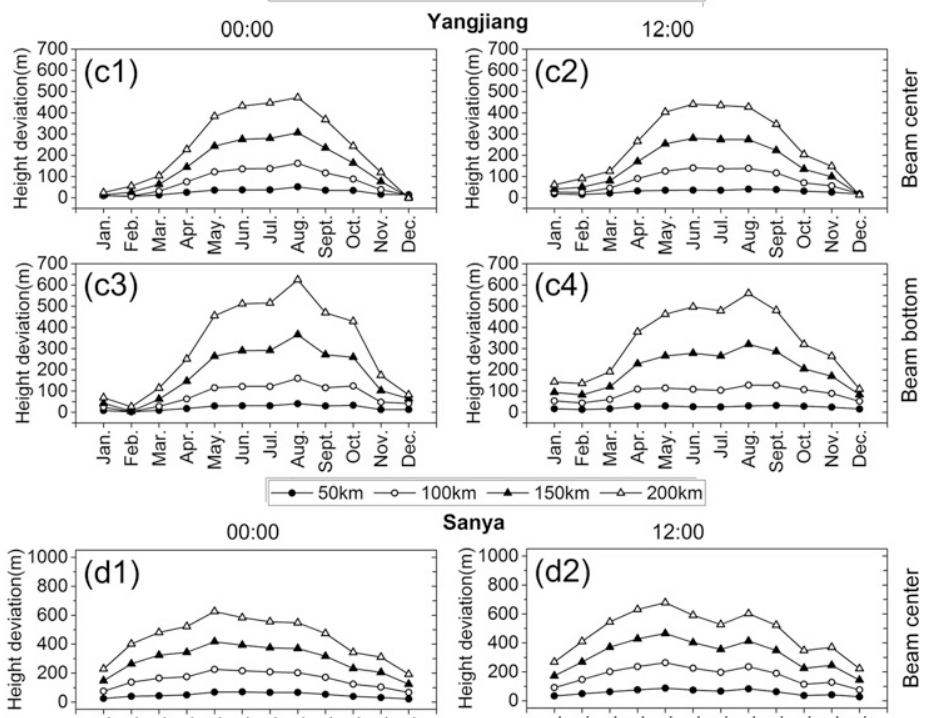

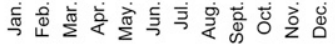

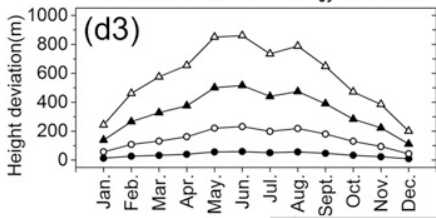

Sanya $\quad 12: 00$
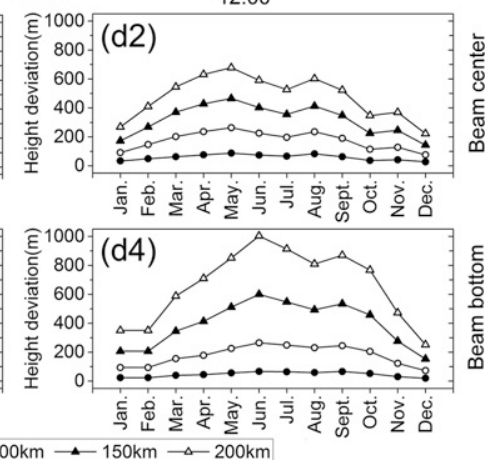

FIG. 6. Deviations of monthly average elevations of radar beam center and bottom as a function of range from those under standard conditions for radars at (a) Beijing, (b) Wuhan, (c) Yangjiang, and (d) Sanya at (left) 0000 and (right) 1200 UTC. Beam center is shown in (a1), (b1), (c1), (d1), (a2), (b2), (c2), and (d2). Beam bottom is shown in (a3), (b3), (c3), (d3), (a4), (b4), (c4), and (d4). The four radars and their nearest sounding stations are marked by thick circles in Fig. 1a. 
Sanya, Yangjiang, and Wuhan, periods with obviously greater deviations also last at least half a year.

With regard to the beam center (Figs. 6a1,a2, 6b1,b2, $6 \mathrm{c} 1, \mathrm{c} 2$, and $6 \mathrm{~d} 1, \mathrm{~d} 2)$, it is directly related to the positioning of the radar echo. For Beijing (Figs. 6a1,a2), the largest positive error in a year is $\sim 140 \mathrm{~m}$ at a range of $100 \mathrm{~km}$ (the same range as below), with a relative deviation of $8 \%$, and the largest negative deviation is about $-20 \mathrm{~m}$, with a relative deviation of $-1.4 \%$. For the site on Hainan Island, Sanya (Figs. 6d1,d2), the deviations are 55-250 m, with a relative deviation of $2.5 \%-15 \%$. For the other sites, the deviations are no greater than $8.5 \%$ overestimation and $0.4 \%$ underestimation. Also, the farther the distance is, the larger the deviations are. For example, the deviations are $200-650 \mathrm{~m}$ at a $200-\mathrm{km}$ range, with relative values of $5 \%-20 \%$ at Sanya. In comparison with the results in the paragraph above, the characteristic deviations of actual beam height are consistent with the values based on statistical VRGs.

From the above results, it is concluded that the deviations of radar beam height are well within the uncertainty of the radar echo height owing to the $\sim 1^{\circ}$ beamwidth (Gao et al. 2008; Doviak and Zrnić 1993) and are thus acceptable for location determination. At this point, propagation conditions for China's weather radar network are generally within the normal range (Bech et al. 2003).

\section{2) DIFFERENCES WITHIN RADAR BEAM}

Although the elevation angle is only $0.5^{\circ}$ and the beamwidth is less than $1^{\circ}$, the same value of $G$ causes approximate height deviations between the beam center and bottom and vertical beamwidths to remain almost unchanged relative to standard conditions. However, there are clear differences between the center (Figs. 6a1, a2, b1,b2, c1,c2, and d1,d2) and bottom (Figs. 6a3,a4, b3, $\mathrm{b} 4, \mathrm{c} 3, \mathrm{c} 4$, and $\mathrm{d} 3, \mathrm{~d} 4)$ of the actual radar beams traced by sounding data. In Fig. 6, the lower parts of the beam have greater deviations than the upper parts, and the deviations of the lower part of the beam also grow more rapidly as distances increase. Moreover, the deviations of the actual beam bottom are much greater than those calculated from the statistical VRG. Here, Wuhan has beam bottom deviations from $\sim 60$ to $-70 \mathrm{~m}$ at a $50-\mathrm{km}$ distance and from $\sim 500$ to $-800 \mathrm{~m}$ at a $200-\mathrm{km}$ distance between May and October. Deviations at Yangjiang are slightly smaller. Sanya has the largest beam bottom deviations, from up to $\sim 70$ to $-80 \mathrm{~m}$ at a $50-\mathrm{km}$ distance and from $\sim 700$ to $-1000 \mathrm{~m}$ at a $200-\mathrm{km}$ distance in June. The explanation for these results is that even within the first kilometer, there are stronger VRGs at elevations nearer the ground, which are important in affecting radar observations (Park and Fabry 2011; AbouAlmal et al. 2014). The beam top plays a minor role and therefore will not be discussed here.

Given that beam bottom heights are from $\sim 170$ to $2440 \mathrm{~m}$ between 50 - and $200-\mathrm{km}$ ranges under standard conditions, beam bottoms bend to heights $\sim 100 \mathrm{~m}$ at a $50-\mathrm{km}$ distance and $1500 \mathrm{~m}$ at $200 \mathrm{~km}$. The differences are remarkable relative to the terrain around the radars (Fig. 1b). Of course, statistical reduction of VRGs by superrefraction would be remarkable (Bech et al. 2002). In coastal areas or around the middle and lower reaches of the Yangtze River valley, there are situations similar to Wuhan, Sanya, and Yangjiang. Users of data from these radars should exercise more caution in interpretation. Somewhat less severe problems of the same nature are expected from the other radars.

\section{Discussion and conclusions}

The accuracy of the spatial location of weather radar echoes depends on radar electromagnetic wave propagation paths, and the vertical gradient of atmospheric refraction is a critical factor that determines groundbased weather radar wave beam paths. The weather radar network in China covers a vast area, across which the geography and climatic conditions change dramatically. Six-year continuous sounding data at 0000 and 1200 UTC were used to study the spatial distribution and seasonal variations of the VRG in the first kilometer of altitude and how these refractive conditions affect beam paths for the operational weather radar network in China.

Under the effects of both regional climatic conditions and topography, VRG values are larger in dry regions and seasons and smaller in moist regions and rainy seasons. Values generally increase with surface elevation by about $6 \mathrm{~km}^{-1}$ per kilometer. In most regions, values are the smallest in July and August and the largest in January and February. However, the time that the largest or smallest value appears is not entirely the same in different regions. In most inland regions, morning values are smaller by about $5-10 \mathrm{~km}^{-1}$ than evening ones, but there are slight differences near coasts. When compared with the surrounding areas, smaller values are frequent in basins, lakes, and river valleys, and larger values are common in hilly or mountainous areas. The largest VRG values are over the Tibetan Plateau, between -35 and $-20 \mathrm{~km}^{-1}$ annually. Over Inner Mongolia and the Yunnan-Guizhou Plateau, values are nearer to those of standard conditions than over other regions. There are relatively small values in the middle and lower reaches of the Yangtze River and over the Yellow and southern Bohai Seas, from about -70 to $-40 \mathrm{~km}^{-1}$ throughout the year. The 
smallest values are over Hainan Island, from about -80 to $-50 \mathrm{~km}^{-1}$. The edge of the Tarim basin has widely varying values, from -80 to $-20 \mathrm{~km}^{-1}$, distinct from other locations in northwest China. During the rainy season when weather radar observations are very important, for most operational weather radars, VRG values are generally smaller than the standard value. Only a few radars have a VRG equal to or slightly larger than the standard value, except on the Tibetan Plateau. VRGs smaller than the standard value are dominant in China's operational weather radar network. These results agree overall with those suggested by the ITU and provide topography-dependent VRG maps with finer spatial distributions to meet the needs of operational weather radars.

Relative to actual conditions, radar beam elevations estimated using standard refraction tend to be overestimated for most weather radars during longer periods, especially in the rainy season. However, deviations of the beam center are $<20 \%$ of the beam depth, which is well within the uncertainty of the radar echo height owing to the $\sim 1^{\circ}$ beamwidth. This means that they are within acceptable ranges for China's weather radar network. In coastal areas and around the middle and lower reaches of the Yangtze River, radar observations should be used with much more caution because of greater risks of beam blockage and clutter contamination, given that the lower part of the radar beam is relatively close to the ground.

Acknowledgments. This study was supported by the Projects in the National Science and Technology Pillar Program (2012BAC22B00). The sounding observations were provided by the National Meteorological Information Center at the Chinese Meteorological Administration and reorganized by the Information Center of the Chinese Academy of Meteorological Sciences. Accdon helped to edit this manuscript. Prof. Yaili Luo suggested changes. We thank them all.

\section{REFERENCES}

AbouAlmal, A., A. A. Raed, and M. R. J. Stephen, 2014: New approaches and algorithms for the analysis of vertical refractivity profile below $1 \mathrm{~km}$ in a subtropical region. IEEE Trans. Antennas Propag., 62, 6501-6505, https://doi.org/ 10.1109/TAP.2014.2360550.

Abu-Almal, A., and A. Kifah, 2010: Calculation of effective earth radius and point refractivity gradient in UAE. Int. J. Antennas Propag., 245070, https://doi.org/10.1155/2010/245070.

Adediji, A. T., M. O. Ajewole, and S. E. Falodun, 2011: Distribution of radio refractivity gradient and effective earth radius factor (k-factor) over Akure, south western Nigeria. J. Atmos. Sol.-Terr. Phys., 73, 2300-2304, https://doi.org/10.1016/ j.jastp.2011.06.017.
Ali, S., S. A. Malik, K. S. Alimgeer, S. A. Khan, and R. L. Ali, 2012: Statistical estimation of tropospheric radio refractivity derived from 10 years meteorological data. J. Atmos. Sol.-Terr. Phys., 77, 96-103, https://doi.org/10.1016/j.jastp.2011.12.001.

Atkinson, B. W., and M. Zhu, 2006: Coastal effects on radar propagation in atmospheric ducting conditions. Meteor. Appl., 13, 53-62, https://doi.org/10.1017/S1350482705001970.

Ayantunji, B. G, P. N. Okeke, and J. O. Urama, 2011: Diurnal and seasonal variation of surface refractivity over Nigeria. Prog. Electromagn. Res., 30B, 201-222, http://m.onlinewww.jpier.org/ PIERB/pierb30/11.11030902.pdf.

Bean, B. R., and J. D. Horn, 1959: Radio-refractive-index climate near the ground. J. Res. Natl. Bur. Stand., 63D, 259-271, https://doi.org/10.6028/jres.063D.025.

—

Bech, J., B. Codina, J. Lorente, and D. Bebbington, 2002: Monthly and daily variations of radar anomalous propagation conditions: How "normal" is normal propagation? Proc. Second European Conf. of Radar Meteorology, Delft, Netherlands, ERAD, 35-39, https://www.copernicus.org/erad/online/erad-35.pdf.

,,,--- and,- 2003 : The sensitivity of single polarization weather radar beam blockage correction to variability in the vertical refractivity gradient. J. Atmos. Oceanic Technol., 20, 845-855, https://doi.org/10.1175/1520-0426(2003)020<0845: TSOSPW $>2.0 . \mathrm{CO} ; 2$.

,-- , and,$- 2007 \mathrm{a}$ : Forecasting weather radar propagation conditions. Meteor. Atmos. Phys., 96, 229-243, https:// doi.org/10.1007/s00703-006-0211-x.

_, U. Gjertsen, and G. Haase, 2007b: Modelling weather radar beam propagation and topographical blockage at northern high latitudes. Quart. J. Roy. Meteor. Soc., 133, 1191-1204, https://doi.org/10.1002/qj.98.

Bellon, A., G. Lee, A. Kilambi, and I. Zawadzki, 2007: Real-time comparison of VPR-corrected daily rainfall estimates with a gauge Mesonet. J. Appl. Meteor. Climatol., 46, 726-741, https://doi.org/10.1175/JAM2502.1.

Bodine, D., D. R. D. Michaud, P. L. Palmer, J. Heinselman, N. Brotzge, B. L. Gasperoni, M. X. Cheong, and J. Gao, 2011: Understanding radar refractivity: Sources of uncertainty. J. Atmos. Oceanic Technol., 50, 2543-2560, https://doi.org/ 10.1175/2011JAMC2648.1.

Brooks, I. M., A. K. Goroch, and D. P. Rogers, 1999: Observations of strong surface radar ducts over the Persian Gulf. J. Appl. Meteor. Climatol., 38, 1293-1310, https://doi.org/10.1175/ 1520-0450(1999)038<1293:OOSSRD > 2.0.CO;2.

Caumont, O., and Coauthors, 2006: A radar simulator for high resolution non-hydrostatic models. J. Atmos. Oceanic Technol., 23, 1049-1067, https://doi.org/10.1175/JTECH1905.1.

Chang, P. L., and P. F. Lin, 2011: Radar anomalous propagation associated with foehn winds induced by Typhoon Krosa (2007). J. Appl. Meteor. Climatol., 50, 1527-1542, https://doi.org/ 10.1175/2011JAMC2619.1.

Chang, Z. G., and J. Zhang, 2004: Simulative model and applied experimentation of atmospheric refractive index near the ground layer. J. PLA Univ. Sci. Technol., 5, 86-89.

Cheng, X. H., and Y. S. Zhang, 2014: Analysis of the errors in estimating atmospheric refractive index from radiosonde measurements. Chin. J. Radio Sci., 29, 951-956.

Dai, T. P., P. C. Zhang, P. L. Shen, and H. D. Jiang, 1993: Three statistical models for the vertical distribution of the atmospheric refractive index over northwest region of China. Plateau Meteor., 12, 48-55, http://gyqx.westgis.ac.cn/EN/ Y1993/V12/I1/48. 
— - - - and Y. Zhan, 1996: Distribution of atmospheric refractive index in 20 regions of China. J. Nanjing Inst. Meteor., 19, 456-463.

Doviak, R. J., and D. S. Zrnić, 1993: Doppler Radar and Weather Observations. Academic Press, 562 pp.

Fabry, F., C. Frush, I. Zawadzki, and A. Kilambi, 1997: Extraction of near-surface index of refraction using radar phase measurements from ground targets. J. Atmos. Oceanic Technol., 14, 978-987, https://doi.org/10.1175/1520-0426(1997)014<0978: OTEONS $>2.0 . \mathrm{CO} ; 2$.

Falodun, S. E., and M. O. Ajewole, 2006: Radio refractive index in the lowest 100-m layer of the troposphere in Akure, south western Nigeria. J. Atmos. Sol.-Terr. Phys., 68, 236-243, https://doi.org/10.1016/j.jastp.2005.10.002.

Fornasiero, A., P. P. Alberoni, R. Amorati, L. Ferraris, and A. C. Taramasso, 2005: Effects of propagation conditions on radar beam-ground interaction: Impact on data quality. $A d v$. Geosci., 2, 201-208, https://doi.org/10.5194/adgeo-2-201-2005.

- — - and J. Bech, 2006: Statistical analysis and modelling of weather radar beam propagation conditions in the Po Valley (Italy). Nat. Hazards Earth Syst. Sci., 6, 303-314, https://doi.org/10.5194/nhess-6-303-2006.

Gao, J. D., K. Brewster, and M. Xue, 2006: A comparison of the radar ray path equations and approximations for use in radar data assimilation. Adv. Atmos. Sci., 23, 190-198, https:// doi.org/10.1007/s00376-006-0190-3.

$\ldots, \ldots$, and $\longrightarrow, 2008$ : Variation of radio refractivity with respect to moisture and temperature and influence on radar ray path. Adv. Atmos. Sci., 25, 1098-1106, https://doi.org/ 10.1007/s00376-008-1098-x.

Grabner, M., and V. Kvicera, 2011: Atmospheric refraction and propagation in lower troposphere. Electromagnetic Waves, V. Zhurbenko, Ed., InTech, 139-156, https://doi.org/10.5772/16379.

Hao, M., J. D. Gong, R. W. Wang, X. M. Wang, and Y. Liu, 2015: The quality assessment and correction of the radiosonde humidity data biases of L-band in China. Acta Meteor. Sin., 73, 187-199.

ITU, 2012: The radio refractive index: Its formula and refractivity data. International Telecommunication Union Recommendation ITU-R P.453-10, 30 pp., https://www.itu.int/dms_pubrec/ itu-r/rec/p/R-REC-P.453-10-201202-S!!PDF-E.pdf.

Lin, Z. Y., and D. Zheng, 1992: The tracks of moisture transportation and its vapour geoecological characteristics on the Qinghai-Xizang Plateau. Arid Zone Res., 9, 1-7, https:// doi.org/10.13866/j.azr.1992.02.001.

Lopez, P., 2009: A 5-yr 40-km-resolution global climatology of superrefraction for ground-based weather radars. J. Appl. Meteor. Climatol., 48, 89-110, https://doi.org/10.1175/ 2008JAMC1961.1.

Magaldi, A. V., M. Mateu, J. Bech, and J. Lorente, 2016: A long term (1999-2008) study of radar anomalous propagation conditions in the western Mediterranean. Atmos. Res., 169, 73-85, https://doi.org/10.1016/j.atmosres.2015.09.027.

Mesnard, F., and H. Sauvageot, 2010: Climatology of anomalous propagation radar echoes in a coastal area. J. Appl. Meteor. Climatol., 49, 2285-2300, https://doi.org/10.1175/2010JAMC2440.1.

Moszkowicz, S., G. J. Ciach, and W. F. Krajewski, 1994: Statistical detection of anomalous propagation in radar reflectivity patterns. J. Atmos. Oceanic Technol., 11, 1026-1034, https://doi.org/ 10.1175/1520-0426(1994)011<1026:SDOAPI>2.0.CO;2.
Park, S., and F. Fabry, 2011: Estimation of near-ground propagation conditions using radar ground echo coverage. J. Atmos. Oceanic Technol., 28, 165-180, https://doi.org/10.1175/2010JTECHA1500.1.

Saleem, M. U., 2016: Statistical investigation and mapping of monthly modified refractivity gradient over Pakistan at the 700 hectopascal level. Open J. Antennas Propag., 4, 46-63, https://doi.org/10.4236/ojapr.2016.42005.

Serdega, V., and G. Ivanovs, 2007: Refraction seasonal variation and that influence on to $\mathrm{GHz}$ range microwaves availability. Electron. Electr. Eng., 78 (6), 39-42, http://eejournal.ktu.lt/ index.php/elt/article/view/10812/5592.

Sharif, H. O., F. L. Ogden, W. F. Krajewski, and M. Xue, 2004: Statistical analysis of radar rainfall error propagation. J. Hydrometeor., 5, 199-212, https://doi.org/10.1175/1525-7541 (2004)005<0199:SAORRE > 2.0.CO;2.

Smith, E. K., and S. Weintraub, 1953: The constants in the equation for atmospheric refractive index at radio frequencies. Proc. IRE, $\mathbf{4 1}$, 1035-1037, https://doi.org/10.1109/JRPROC.1953.274297.

Steiner, M., and J. A. Smith, 2002: Use of three-dimensional reflectivity structure for automated detection and removal of nonprecipitating echoes in radar data. J. Atmos. Oceanic Technol., 19, 673-686, https://doi.org/10.1175/1520-0426(2002) 019<0673:UOTDRS $>2.0 . \mathrm{CO} ; 2$.

Sweezy, W. B., and B. R. Bean, 1963: Correction of atmospheric refraction errors in radio height finding. J. Res. Natl. Bur. Stand., 67D, 139-151, https://doi.org/10.6028/jres.067D.017.

Valma, E., M. Zilinskas, S. Tamosiunas, M. Tamosiunaite, and M. Tamosiuniene, 2010: Determination of radio refractivity using meteorological data. Electron. Electr. Eng., 106, 125-128, http://eejournal.ktu.lt/index.php/elt/article/view/9141/4486.

von Engeln, A., and J. Teixeira, 2004: A ducting climatology derived from the European Centre for Medium-Range Weather Forecasts global analysis fields. J. Geophys. Res., 109, D18104, https://doi.org/10.1029/2003JD004380.

Wang, G. L., W. Wong, L. P. Liu, and H. Y. Wang, 2013: Application of multi-scale tracking radar echoes scheme in quantitative precipitation nowcasting. Adv. Atmos. Sci., 30, 448-460, https://doi.org/10.1007/s00376-012-2026-7.

Wang, H. Y., L. P. Liu, and L. P. He, 2014: Beam blockage studies of Doppler weather radar in mountainous region of Zhejiang. Plateau Meteor., 33, 1737-1747.

Xiao, Y. J., L. P. Liu, and Y. Shi, 2008: Study of methods for threedimensional multiple-radar reflectivity mosaics. Acta Meteor. Sin., 22, 351-361.

Yang, Q., X. Liu, C. Cui, L. I. Jun, and L. Rui, 2010: The computation and characteristics analysis of water vapor contents in the Tarim Basin, China. Acta Geogr. Sin., 65, 853-863.

Zeng, Y., U. Blahak, M. Neuper, and D. Jerger, 2014: Radar beam tracing methods based on atmospheric refractive index. J. Atmos. Oceanic Technol., 31, 2650-2670, https://doi.org/ 10.1175/JTECH-D-13-00152.1.

Zhang, J., K. Howard, and J. J. Gourley, 2005: Constructing threedimensional multiple-radar reflectivity mosaics: Examples of convective storms and stratiform rain echoes. J. Atmos. Oceanic Technol., 22, 30-42, https://doi.org/10.1175/JTECH-1689.1.

Zhang, P. C., T. P. Dai, and X. M. Zheng, 1991: Three statistical models for the vertical distribution of the atmospheric refractive index in some parts of China. Sci. Meteor. Sin., 11, 402-413, http://www.jms1980.com/ch/reader/create_pdf.aspx? file_no=19910454\&flag=\&journal_id=qxkx\&year_id=1991. 